Foi com imenso prazer e alegria que aceitei o convite de apresentar esta entrevista do Dr. Messias Rodrigues. Conheço o Dr. Messias há 18 anos, quando atuava como estagiário no curso do amigo e eterno professor Dr. Renato Rodrigues de Almeida, em Bauru. A vida quis que voltasse a encontrar o Messias anos depois, quando convidado pelo Dr. Gerval de Almeida, fui contribuir para o Curso de Especialização da UNITAU, e qual não foi minha surpresa, lá estava ele, entre os alunos selecionados para o Curso. Pude então, ter a honra de uma convivência rica e amistosa, que dura até hoje. Na época, o Dr. Messias já tinha um preparo e uma vivência Ortodôntica muito boa, e acredito que o Curso de Especialização serviu para ele aprimorar ainda mais seu conhecimento, convivendo com ilustres mestres como o Dr. Gerval de Almeida, S. Interlandi. Ele vinha com uma vivência em Ortopedia Funcional e já alguma coisa de Tip-Edge, que somado à vivência com o Straight-wire resultou na sua própria filosofia, que culminou com a edição de seu livro "Técnica Straight-wire simplificada", pela editora Dental Press. O Messias é sucesso de público e de amizades, lider natural e amigo fiel, dedica-se com afinco a tudo que ama, como sua profissão, sua família, amigos, colegas e .... seu barco. Ele sabe equilibrar a vida profissional e pessoal, se tornando um exemplo de profissional competentíssimo, clínico hábil, professor de qualidade ímpar, sem perder seu sotaque "Once more, more in Piracicaba", sua simplicidade e doçura. Messias, você é 10!

Weber Ursi

1) Hipoteticamente, nos tratamentos de Classe II com extrações, em que o senhor estaria a usar os elásticos de Classe II associados à dobra de ancoragem, como se controla o efeito adverso da dobra de ancoragem, se eventualmente o paciente não usar elásticos, quer seja por indisciplina ou por estar em viagem? Carlos Cabrera

Professor Cabrera, fiquei muito feliz quando identifiquei seu nome dentre os ilustres colegas e amigos que me enderessaram perguntas; de imediato já sabia que dividiríamos este espaço com conceitos mecânicos e clínicos.

Realmente, a dobra de ancoragem e os elásticos de Classe II devem ser aplicados concomitantemente para que os dentes anteriores possam fazer o movimento de intrusão e retração através do longo eixo dos incisivos. A falta de colaboração do paciente não chega a ser um problema em minha clínica ortodôntica, pois os elásticos de Classe II são muito leves (35 gramas de força em média, com uso contínuo) e os pacientes praticamente não o sentem. Todavia, como acontece com qual-

\section{Messias Rodrigues}

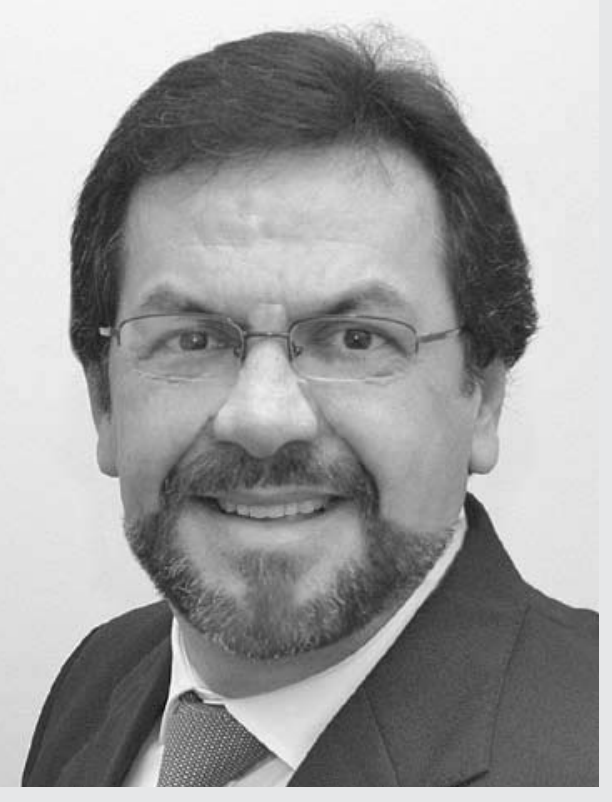

- Professor do curso de especialização em Ortodontia da UNITAU.

- Consultor da TP Orthodontics no Brasil.

- Ministrador de cursos organizados pela TP Orthodontics no Brasil, Portugal e Austrália.

- Idealizador da Técnica Straight-Wire Simplificada.

- Autor do livro Técnica Straight-Wire Simplificada.

quer outro artifício ortodôntico onde dependemos da colaboração do paciente, existem alguns poucos pacientes não colaboradores. Nestas circunstâncias, logo no primeiro ou segundo mês, a retração dos dentes anteriores, conseguida através do elástico x dobra de ancoragem, além de não ocorrer, começa a acontecer um pequeno movimento de protrusão dos incisivos superiores. Nestas condições, mudo o planejamento mecânico para retração do canino com cadeia elástica horizontal, associada aos arcos dupla chave.

Cabe lembrar que esta opção mecânica com arco dupla chave, embora beneficiada pela liberdade de movimentação dos caninos, produz níveis de 
força muito superiores à outra opção e requer alguns artifícios de ancoragem, tal como o uso de barra transpalatina nos primeiros molares e bandagem dos segundos molares superiores desde o princípio.

2) $O$ que o senhor pensa sobre a indicação ou não de ajustes oclusais após o término dos tratamentos ortodônticos. As síndromes de dores e disfunções são motivos de preocupações em sua atividade clínica? Carlos Cabrera

Que bom que você me fez esta pergunta, pois tenho agora a oportunidade de esclarecer esta preocupação que muitos ortodontistas têm a respeito dos elásticos de Classe II, pelo efeito que estes podem causar às ATMs. O uso do elástico de Classe II nas mecânicas que usam slot horizontal para arco de canto, só tem algum resultado clínico se forem usados com altos níveis de força. Isto se dá pelo próprio design do slot e pelo uso concomitante aos arcos retangulares na procura pelo movimento de corpo do dente. Desta forma, com o slot "cheio" pelo arco retangular aumenta-se muito o atrito e se faz necessária uma força proporcional do elástico para que se consiga tal movimento. Já na Mecânica Straight-Wire Simplificada, usamos braquetes mini, que geram menos atrito, com slot 0,022" e arco 0,016". Esta "folga" entre o arco e o slot, mais os braquetes especiais para os caninos, permitem o movimento dos dentes em duas etapas (corpo x coroa) a baixíssimos níveis de força dos elásticos de Classe II. Na prática clínica em meu consultório, tais forças eláticas produzem bons resultados clínicos, sem causar danos às ATMs. Cabe ressaltar que somente na fase inicial do tratamento (retração e abertura da mordida) é que usamos os elásticos de Classe II o que representaria $1 / 4$ do tratamento ortodôntico.

A respeito dos ajustes oclusais, antes da remoção do aparelho, verifico se ambas as guias dos caninos estão a desocluir com a mesma altura e se não há prematuridades nos lados de não trabalho. Acredito que, por ser a disfunção têmporo-mandibular um problema multifatorial, o ajuste em Re- lação Cêntrica, além de muito minucioso e difícil, tem uma parcela pequena em tal problema.

3) Apenas como uma referência (não absoluta, obviamente), como o senhor poderia estimar em porcentagem de tratamentos ortodônticos efetuados em vossa clínica, quanto a eles serem: Com ou sem extrações, masculino e feminino e adolecentes e adultos? Carlos Cabrera

Eu infelizmente não sei lhe dizer os percentuais, mas tenho notado um aumento significativo de pacientes adultos e do gênero feminino, principalmente por problemas de dor, e disfunção nas ATMs. Nos adolescentes, aproximadamente 70\% deles são portadores de má oclusão de Classe II. Nas Classes II verticais, causadas pelo aumento da altura facial ântero-inferior, eu costumo fazer extrações para evitar distalizações e se possível, mesializar molares na tentativa de diminuir a altura facial ântero-inferior e promover a auto-rotação de mandíbula. Nas Classes II horizontais, com altura facial ântero-inferior diminuída e mandíbula pequena, faço tratamento sem extrações para estimular o movimento da mandíbula para frente e para baixo.

Infelizmente, das Classes II que aparecem em minha clínica, a maioria é vertical. Eu arriscaria uma proporção de $60 \%$ para $40 \%$.

4) Como o senhor age diante de um paciente adulto, portador de uma Classe II, com retrusão mandibular, apinhamentos severos em que o planejamento exige a indicação de avanço cirúrgico sagital de mandíbula, entretanto, - paciente não quer submeter-se a cirurgia e quer apenas corrigir os apinhamentos. Como dividir responsabilidades? Carlos Cabrera

Com o aumento da freqüência dos pacientes adultos em meu consultório, da forma como descrevo na resposta da pergunta anterior, acho interessante se fazer uma proposta de plano de tratamento diferenciado para esta categoria de 
pacientes. Eles, além de mais impacientes, se me permite o trocadilho, não se adaptam tão facilmente ao tratamento como os adolescentes. Atualmente, nesse tipo de tratamento, tenho como objetivo alcançar a correção da queixa trazida pelo paciente que na verdade é a única responsável por sua vinda em nossa clínica. Como você próprio bem coloca, devemos dividir responsabilidades. O paciente tem condições de entender todos os prós e contras de ambas as opções de tratamento e optar pela que melhor the convier.

5) A Ortodontia atravessa com freqüência, períodos em que se nota o interesse geral dos ortodontistas por determinadas "novidades" clínicas. No momento, um dos aspectos a serem lembrados é o denominado "controle vertical". Qual sua opinião a respeito dos resultados conseguidos? S. Interlandi

Caro professor, que honra tê-lo como entrevistador. Em alguns casos clínicos, ainda na dentadura mista, uso alguns artifícios para o controle vertical, tais como barra transpalatina e aparelho "bite block." Embora não tenha nenhuma experiência com ancoragem esquelética através dos mini implantes, eu creio que eles vieram para ficar e deverão provavelmente atuar como artifício ortodôntico alternativo, não só como ancoragem no sentido sagital, mas também no que tange a intrusão dentária.
6) Em seu livro recém-publicado, vi com prazer, alguns casos apresentados em que o ilustre colega empregou o "Gráfico Vetorial Ortodôntico". Julga de interesse didático a adoção desse método na planificação do tratamento ortodôntico? S. Interlandi

A utilização do gráfico vetorial ortodôntico, tem sido muito proveitosa, principalmente nos casos clínicos onde existem assimetrias dentárias associadas ao apinhamento. A divisão em quadrantes relacionada à linha mediana sagital e à escolha de um dente chave em cada quadrante, evidencia com clareza o local exato onde cada dente deve estar. Sendo assim, não só é interessante do ponto de vista didático como clínico também.

7) Em seus casos clínicos, poderia mencionar alguns valores cefalométricos que, mais de perto, merecem sua atenção na planificação de um bom perfil tegumentar? S. Interlandi

Tomo como referência para planificação do tratamento, uma linha que tangencia o lábio superior, lábio inferior, mento e corta o nariz ao meio. Esta linha, chamada Linha Estética de Referência é construída a partir de um ponto localizado no lábio superior e outro no meio do nariz.

A leitura da posição do lábio superior é feita a partir de uma linha perpendicular à linha do hori-

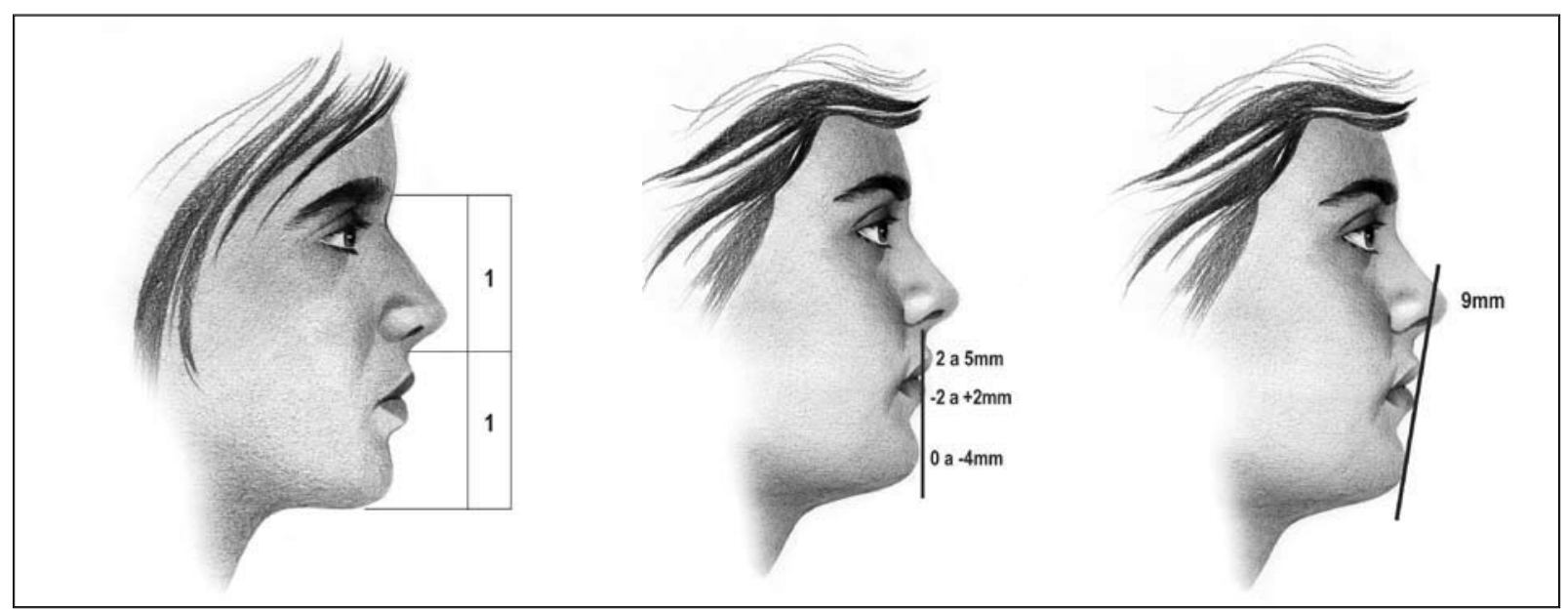

FIGURA 1, 2, 3 
zonte, ou Plano Horizontal Verdadeiro, que passa pelo ponto subnasal. Esta linha foi denominada Linha Subnasal Vertical ${ }^{1}$.

Definida a posição do lábio superior, desenhamos a linha estética do perfil.

Nos casos onde o mento fica afastado em relação à esta linha, baseamo-nos na proporção entre a altura facial anterior média com a altura facial ântero-inferior, para discernirmos se o movimento do mento deveria ser para frente e para cima, ou para frente e para baixo.

São estas as medidas tegumentares que tomo como ponto de partida em meus planejamentos ortodônticos (Fig. 1, 2, 3).

8) Sabidamente, ministrador de cursos em Portugal, que informação poderá nos fornecer sobre a situação atual das publicações ortodônticas naquele país? S. Interlandi

A Sociedade Portuguesa de Ortopedia Dento Facial, publica uma revista com periodicidade semestral. Mesmo tendo uma tiragem pequena, trata-se de uma revista bi-lingue (Português - Inglês) e de excelente nível. Seu idealizador e diretor é o professor Dr. Korrodi Ritto, criador de um aparelho de protrusão mandibular, com um dispositivo telescópico miniaturizado com aplicação e ativação intraoral simplificadas. Sem dúvida um dos grandes nomes da Ortodontia portuguesa, trabalhando pela ciência de Angle naquele país.

\section{9) Que condições clínicas o fazem optar} pela opção mecânica do tratamentos com arcos dupla-chave ao invés dos elásticos de Classe II associados à dobra de ancoragem? Júlio Vargas Neto

As extrações dentárias têm sido um recurso bastante útil no tratamento das discrepâncias esqueléticas e dentoalveolares. A maneira de fechamento dos espaços resultantes destas extrações tem merecido a atenção de muitos. em face de alguns tipos faciais permitirem o avanço dos dentes posteriores, com perda de ancoragem, ocupando o espaço necessário para as retrações. Os tratamentos dos casos de Classe II com extrações, freqüentemente, requerem cuidados extremos com a ancoragem. A retração anterior precisa ser feita com pouco ou nenhum avanço dos dentes posteriores. É, portanto, um desafio controlar a ancoragem posterior com os graves problemas que o setor anterior pode apresentar, como os severos trespasses verticais e horizontais.

Das alternativas expostas em trabalhos publicados para a solução desses problemas, os arcos de retração com alças verticais em fios retangulares foram, e são até hoje, muito usados, provavelmente por conseguirem fazer tanto o movimento dos dentes anteriores, como o dos posteriores, com ótimo controle de posição de coroa e raiz.

O problema que o braquete pré-ajustado do canino traz é inerente à mecânica ortodôntica. Isto fez com que a ancoragem posterior tornasse o principal ponto para a obtenção do sucesso na mecânica com braquetes pré-ajustados.

A forma com que trabalho, usando este tipo de arco, tem algumas diferenças clínicas daquela preconizada por outros autores. A principal delas, é sem dúvida, a troca dos caninos pré-ajustados convencionais por pré-ajustados "Tip-Edge". Desta maneira as solicitações de ancoragem dos molares, por parte dos caninos em retração, ficam minimizadas.

Também usando os braquetes "Tip-Edge" nos caninos podemos coordenar os arcos dupla-chave superiores com uma leve curva de Spee incorporada a ele, até que a parte anterior alcance a região cervical dos incisivos sem deflexão. Desta forma, conseguimos um controle simultâneo sobre a angulação da bateria anterior e direção de intrusão dos dentes anteriores. Tais braquetes, em conjunto com os arcos dupla chave, fazem com que o deslocamento dos caninos, para a distal, seja independente dos dentes anteriores, em qualquer situação. Sendo assim, torna-se possível a retração anterior com controle da quantidade de ancoragem a ser preservada, bem como dar atenção especial aos 
dentes anteriores.

Portanto, eu opto por este tipo de mecânica, principalmente quando preciso de retração dos dentes anteriores com controle. Freqüentemente os uso nos casos com sorriso gengival e Classe II,

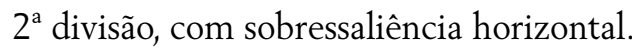

10) A mecânica Straight Wire simplificada, surgiu da permuta dos braquetes Straight Wire convencionais dos caninos por Straight Wire Tip-Edge. Esta idéia é original ou alguém já havia preconizado o uso de tal modificação anteriormente? Rosana Villela Chagas

Dr. Peter Kesling idealizou o braquete TipEdge no final da década de 80. Junto com este novo braquete pré-ajustado, na época, ele desenvolveu uma técnica que levou o mesmo nome do braquete. Em 1994, O Dr. Thomas Rocke, seu parceiro no desenvolvimento da técnica Tip-Edge, publicou um artigo na revista American Journal of Orthodontics, onde ele usava braquetes "StraightWire" convencionais apenas nos incisivos superiores e Tip-Edge nos demais.

Esta prescrição de braquetes, proposta pelo Dr. Rocke, tinha o objetivo de controlar o torque dos incisivos superiores na técnica Tip-Edge pura. Nesta época, após ler este artigo, pensei na permuta dos braquetes dos caninos na mecânica Straight Wire, pois freqüentemente, na prática em minha clínica, deparava-me com os problemas causados pela inclinação dos caninos pré-ajustados convencionais. Após experimentar esta mudança em alguns casos e ver estes problemas solucionados, adotei esta nova prescrição de braquetes como rotina em minha clínica.

Em 1998, já com casos terminados e documentados, eu e os professores Weber Ursi e Gerval de Almeida publicamos artigo inédito ${ }^{3}$ nesta revista sobre este assunto.

11) O tema ancoragem foi sempre levantado e questionado em todas as técnicas. Algumas exigem mais ancoragem do que outras ou

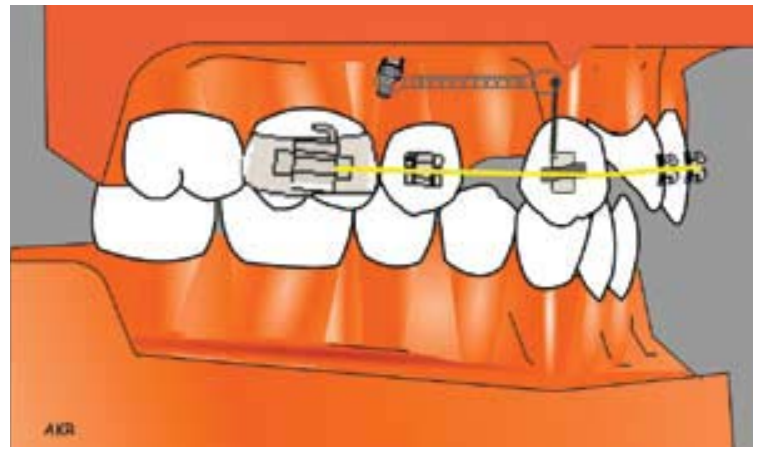

FIGURA 4

uma preparação prévia por vezes algo trabalhosa, para evitar os movimentos indesejáveis. Atualmente, com o desenvolvimento da ancoragem esquelética, tudo se simplificou, quer na própria técnica em si, quer na dependência da colaboração do paciente. Esta nova forma de ancoragem permite ainda reduzir o tempo de tratamento. Vendo nesta perspectiva, considera que existiria alguma vantagem na sua técnica, se utilizasse um braquete "tip edge" no canino, com um gancho alto e uma mola para distalizar a raiz com apoio num microimplante entre o molar e pré-molar (Fig. 4)? A. Korrodi Ritto

Dr. Ritto, é muito bom ter um amigo português e referência da Ortodontia portuguesa como entrevistador. Teoricamente, esta sua idéia seria uma boa alternativa para a verticalização da raiz do canino distalizado. No entanto, as molas verticalizadoras Side-Winder tem mostrado excelente resultado, além de muita facilidade de confecção e instalação.

12) A colaboração do paciente intervém numa percentagem significativa no resultado final. A sua técnica utiliza muito os elásticos inter ou intra-maxilares. Como trata os pacientes pouco colaboradores, principalmente aqueles casos mais complicados com extrações de molares inferiores? Recorre ao uso da ancoragem esquelética? A. Korrodi Ritto

A respeito da primeira parte da pergunta, 
já me referi a isto na pergunta do Dr. Cabrera, mas gostaria de me estender um pouco mais pois esta é uma preocupação que sempre os colegas me trazem. A falta de colaboração do paciente sempre foi o grande problema na clínica ortodôntica, principalmente quando se trata de aparelhos como arco extrabucal ou ortopédicos funcionais. Nos casos dos elásticos de Classe II com 35 gramas de força, o único desconforto que ele traz ao paciente é no ato da colocação e troca, já que eles são imperceptíveis quando instalados na boca. Isto, exposto claramente ao paciente, torna mais fácil a sua conscientização e colaboração quanto ao uso dos elásticos. A respeito da ancoragem esquelética eu não costumo usá-la, pois na mecânica da técnica Straigth Wire simplificada fazemos a correção sagital mais pela liberdade dos dentes anteriores, que pela ancoragem dos posteriores. Contudo eu creio que a ancoragem esquelética através dos mini implantes seja sem dúvida o novo paradigma da Ortodontia, tal como os braquetes pré-ajustados o foram na década de 70 .

13) Os últimos anos trouxeram muitas novidades para a Ortodontia. A distração óssea, a ancoragem esquelética, os braquetes individualizados, os fios confeccionados por robôs e a imagem tridimensional. Sem dúvida que os próximos anos estão destinados a uma baixa de preços dos aparelhos de imagem de diagnóstico digital tridimensional, de forma a podermos usufruir desses sistemas nas nossas clínicas. Como valoriza este novo aporte à Ortodontia? A. Korrodi Ritto

Aguardo com muita ansiedade a baixa de preços dos aparelhos de imagem tridimensional, pois muitos dos centros especializados nesses tipos de exame trazem preços impraticáveis para a maioria dos pacientes. Certamente a utilização deste tipo de imagem nos ajudaria muito, principalmente para a vizualização da quantidade de osso em alguns locais específicos, tais como sínfise mentoniana, região anterior da maxila e caninos ectópicos.
14) No seguimento da questão anterior, como vê o futuro da Ortodontia, sabendo que atualmente tudo está muito simplificado e até é possível mandar modelos para um laboratório e receber aparelhos já com as etapas de tratamento. Será que a Ortodontia vai se generalizar ou se banalizar? A. Korrodi Ritto

A Ortodontia tornou-se acessivel a todos os clínicos, graças ao grande número de cursos de especialização e atualização em Ortodontia que são oferecidos. Infelizmente, nem todos são ministrados por ortodontistas com experiência clínica e conhecimentos básicos de elevada categoria. Alguns cursos "vendem" uma Ortodontia fácil e as vezes até banal. No entanto, em minhas participações em eventos e congressos, tenho notado um nível muito bom entre os colegas. Eu sinceramente creio na evolução natural da Ortodontia, e que estas propostas de simplificação tendem a desaparecer, mesmo porque, a qualidade está custando menos, porque o bom ortodontista teve que baixar o seu preço sob a pena de ver sua clínica quebrar. Hoje temos que ter qualidade sem cobrar mais caro, não só pela concorrência, mas porque o preço sempre esteve superdimensionado na Ortodontia. Hoje no Brasil podemos ver crianças da periferia, de famílias menos privilegiadas, usando aparelhos ortodônticos.

Ao ler esta pergunta, de pronto lembrei-me de uma entrevista ${ }^{2}$ que o nosso saudoso professor Joel Cláudio da Rosa Martins concedeu a esta revista. Sua resposta a uma pergunta sobre este assunto, foi tão esclarecedora que me permiti relembrá-la em alguns tópicos. Ele dizia haver duas correntes na prática ortodôntica. Uma, purista (romântica), envolvida pela maioria elitizada da comunidade científica, que aponta para a individualizaçâo dos tratamentos. Nesta corrente cada paciente seria analisado mais especificamente e um aparelho especial seria desenhado a partir destes dados. Outra, social e econômica (realista) pressionada pela demanda cada vez maior por um tratamento 
ortodôntico acessível, onde se exige baixos custos, sistematização e aceita objetivos mais genéricos. A corrente realista, ao contrário da purista, prega um só tipo de aparelho para todos os pacientes, que conseqüentemente traria resultados limitados de diferentes maneiras.

Acredito que embora me identifique na corrente purista, por tentar tratar cada paciente com objetivos específicos e bem desenhados, também me vejo influenciado pela corrente realista, pois os ortodontistas, sob a égide do realismo, sistematizam os tratamentos, tratam vários pacientes ao mesmo tempo, têm uma exata dimensão de lucro e se preparam para enfrentar a grande concorrência do futuro.

Penso que, se entendi bem a pergunta, este tipo de proposta de aparelhos feitos em etapas nos laboratórios, não se trata de banalização do tratamento mas de uma maneira extrema de ver sob a ótica realista.

15) Escrever um livro é sem dúvida um marco importante na carreira de um ortodontista, marcando e perpetuando os seus ideais e deixando a obra aos seus seguidores $e$ interessados. Como se sentiu no dia em que apresentou o seu livro? Pode-nos falar sobre o seu próximo projeto? A. Korrodi Ritto

Realmente a publicação do livro foi um marco em minha vida. Após dois anos de trabalho, hoje quando folheio o livro, sinto o quanto valeu o sacrifício de horas no computador, ausente à minha família e meus amigos. A sensação mais gratificante é sem dúvida quando vêm a mim alguns alunos com o livro marcado a tinta, trazendo dúvidas e argumentando conceitos dali tirados. É nesta hora que tenho a certeza que valeu a pena, pois foram eles, meus alunos, a razão desta jornada. A única certeza que trago após esta experiência é que dificilmente conseguiria concretizar esse desafio, sem a ajuda de amigos e professores da UNITAU e do colega Laurindo Furquim que acreditou em meu projeto levando-o até o fim.

\section{A. Korrodi Ritto}

- Vice Presidente da Sociedade Portuguesa de Ortopedia Dento Facial

- Graduado na Faculdade de Odontologia Oporto

- PhD pela Universidade Oporto

- Ortodontista em Leiria - Portugal

- Inventor do Ritto Appliance

\section{Carlos Alberto Gregório Cabrera}

- Mestre em Ortodontia pela Universidade de São Paulo USP/Bauru e Universidade Estadual de Londrina-UEL.

- Doutorando em Ortodontia pela Universidade de São Paulo-USP/Bauru.

Júlio Vargas Neto

- Graduado pela Faculdade de Odontologia de Araraquara - UNESP (1992).

- Mestre em Ortodontia e Ortopedia Facial pela Faculdade de Odontologia de Bauru - USP (1998).

- Professor nos cursos de Graduação e Pós-graduação em Ortodontia da Faculdade de Odontologia de Araras - UNIARARAS.

- Professor no curso de Especialização na Escola de Aperfeiçoamento Profissional da Associação Odontológica do Paraná - AONP, em Londrina-PR.

\section{Rosana Villela Chagas}

- Especialista em Ortodontia.

- Mestre e Doutora em Odontologia.

- Professora responsável da Disciplina de Ortodontia do Departamento de Odontologia da Universidade de Taubaté.

- Professora do Curso de Especialização em Ortodontia e Ortopedia Facial do Departamento de Odontologia da Universidade de Taubaté.

\section{Sebastião Interlandi}

- Professor Titular pela Faculdade de Odontologia da Universidade de São Paulo.

- "Master of Science in Dentistry", pela University of Saint Louis - USA.

- Primeiro Presidente eleito (Lima - Peru) da "Associación Latino Americana de Ortodóncia".

- Primeiro ex-aluno estrangeiro a receber o "Orthodontic Alumni Merit Award" da University of Saint Louis - USA.

\section{REFERÊNCIAS}

1. INTERLANDI, S. Ortodontia: bases para iniciação. 1. ed. São Paulo: Panamed, 1999.

2. MARTINS, J. C. R. Entrevista. R Dental Press Ortodon Ortop Facial, Maringá, v. 3, n. 6, p. 1-13, nov./dez. 1998.

3. RODRIGUES, M.; URSI, W.; ALMEIDA, G. Uso de braquetes TipEdge em caninos, para facilitar o controle vertical dos dentes anteriores na mecânica Straight-Wire. R Dental Press Ortodon Ortop Facial, Maringá, v. 3, n. 5, p. 59-64, set./out. 1998. 


\section{Oxidação de braquetes metálicos}

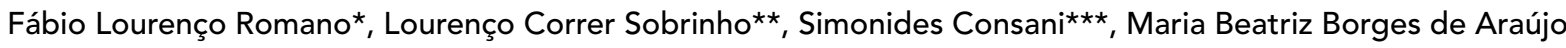

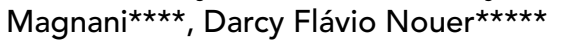

A colagem de braquetes diretamente ao esmalte dentário é um procedimento simples, que traz grandes vantagens estéticas ao paciente e benefícios ao profissional. Porém, deve-se usar técnica adequada e criteriosa, respeitando os passos indicados pelos fabricantes. Além disto, deve-se utilizar materiais de qualidade comprovada por pesquisas clínicas e laboratoriais. $\mathrm{Na}$ grande maioria das vezes a colagem do braquete é realizada com sucesso, entretanto, esta deve ser verificada durante todo o tratamento com a finalidade de evitar que defeitos na estrutura dos mesmos causem danos ao esmalte do paciente.

Não é raro observarmos algumas alterações como fraturas, aletas amassadas, separação da matha do restante do braquete, entre outros problemas, porém, cita-se em especial a oxidação da base do braquete (Fig. 1A, B). Quando na cavidade bucal o acessório não é capaz de resistir aos fluidos bucais, liberando substância de cor negra na superfície do esmalte.

Diante desta situação, o ortodontista deve

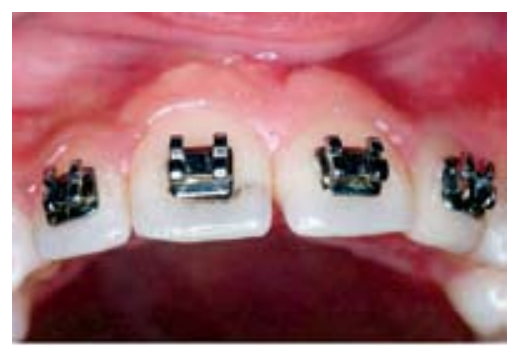

FIGURA 1A

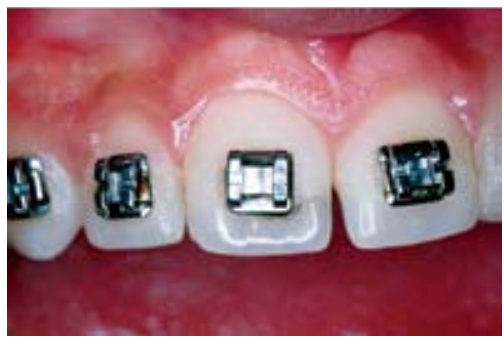

FIGURA 1B

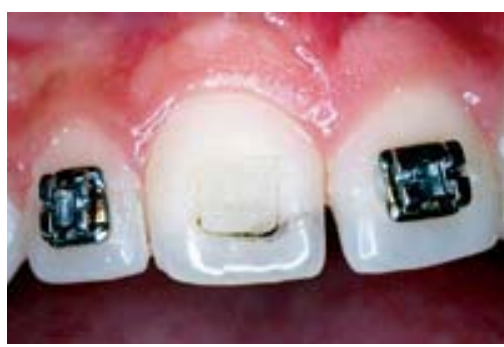

FIGURA 2

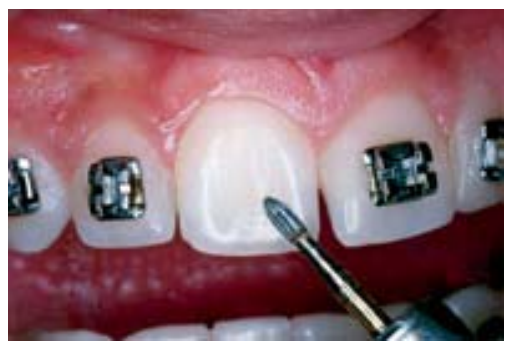

FIGURA 3

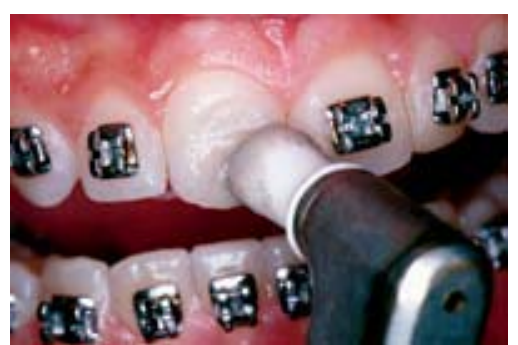

FIGURA 4

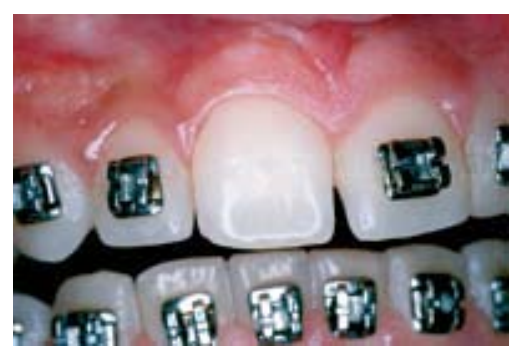

FIGURA 5

* Mestre em Ortodontia pela Faculdade de Odontologia de Piracicaba / UNICAMP. Professor do Curso de Especialização em Ortodontia - Efoa / Ceufe.

** Professor Titular da área de Materiais Dentários - Departamento de Odontologia Restauradora da Faculdade de Odontologia de Piracicaba - UNICAMP

*** Professor Titular da área de Materiais Dentários - Departamento de Odontologia Restauradora da Faculdade de Odontologia de Piracicaba - UNICAMP.

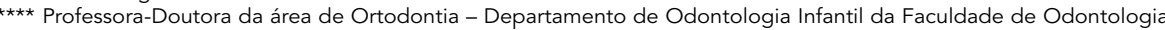
de Piracicaba - UNICAMP.

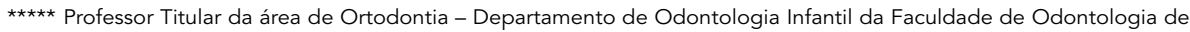
Piracicaba - UNICAMP. 


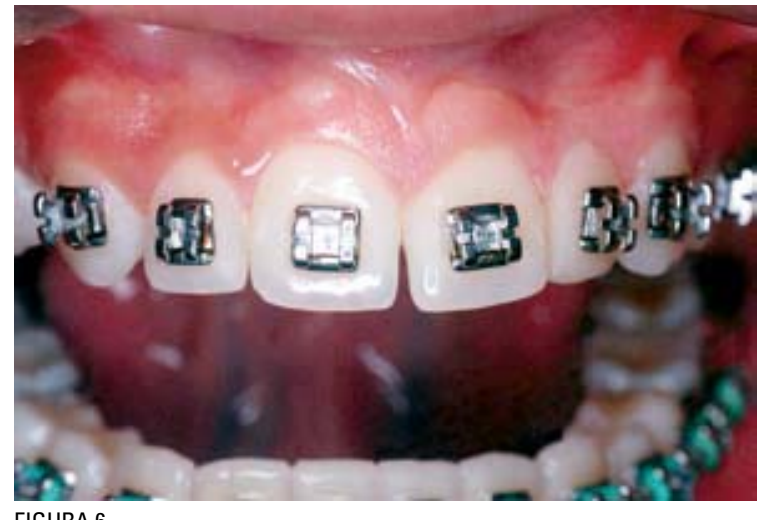

FIGURA 6

tomar providências imediatas para evitar que os produtos da oxidação penetrem na estrutura do esmalte e conseqüentemente provoquem manchas. Desta forma, o braquete deve ser removido com alicates próprios para este fim (How ou Weingart). Após a remoção do acessório o remanescente resinoso pigmentado pela oxidação (Fig. 2), deve ser removido com broca de carboneto de tungstênio (carbide) de 6 ou 12 lâminas (Fig. 3) em motor de baixa rotação somente atu-

\section{REFERÊNCIAS}

1. BELTRAMI, L. E. R.; FREITAS, C. A.; MARTINS, D. R. Bráquetes com sulcos retentivos na base, colados clinicamente e removidos em laboratório por testes de tração, cisalhamento e torção. Ortodontia, São Paulo, v. 29, n. 2, p. 27-39, maio/jun. 1996.

2. MIZRAHI, E. Surface distribution of enamel opacities following orthodontic treatment. Am J Orthod, St. Louis, v. 83, n. 5, p. 323-331, May 1983.

3. MORAES, H. T. Remoção de bráquetes colados. Rev Assoc Paul Cir Dent, São Paulo, v. 51, n. 1, p. 37-40, jan./fev. 1997.

4. RUELA, A. C. O et al. Efeitos sobre a topografia do esmalte de dois métodos de descolagem de bráquetes metálicos (in vivo). Rev CROMG, Belo Horizonte, v. 3, n. 1, p. 1-5, jan./jun. 1997.

5. ZACHRISSON BU. Bonding in Orthodontic. In: GRABER, T.M. SWAIN, B.F. Orthodontic current principle and technique. 1. ed., St. Louis, CV Mosby CO, 1985, 485p. ando com a broca sobre o compósito. Finalmente após remoção de todo compósito remanescente sobre o esmalte, realiza-se profilaxia da superfície vestibular com pasta de pedra-pomes e água com taça de borracha por aproximadamente 15 segundos (Fig. 4), lavagem e secagem pelo mesmo período de tempo. Com tais procedimentos é possível devolver a morfologia normal do esmalte dental (Fig. 5). Em seguida realiza-se colagem de outro bráquete seguindo os passos convencionais do procedimento para continuação da mecanoterapia ortodôntica (Fig. 6).

Se a oxidação não for detectada precocemente pode ocorrer pigmentação definitiva da estrutura do esmalte pela penetração dos produtos derivados da oxidação nos prismas de esmalte, causando aparência estética desfavorável ao paciente e podendo provocar dúvidas em relação ao material utilizado pelo ortodontista. Quando isto ocorre, o tratamento indicado é a remoção do braquete e do remanescente resinoso e em seguida restauração da área comprometida com compósito.
Endereço para correspondência

Fábio Lourenço Romano

Avenida do Café, 131 Bloco E Apto 16 - Vila Amélia

CEP: 14050-230 - Ribeirão Preto/SP

E-mail: flromano@aol.com 